\title{
Social Engagement of Kazakh Students
}

\author{
Aigerim Mukhametbekovna Assylbekova ${ }^{1}$ \\ ${ }^{1}$ L. N. Gumilyov Eurasian National University, Astana, Kazakhstan \\ Correspondence: Aigerim Mukhametbekovna Assylbekova, Munaitpasova Street, 5, Astana, 010000, \\ Kazakhstan
}

Received: February 28, 2015 Accepted: March 20, 2015 Online Published: April 24, 2015

doi:10.5539/res.v7n6p61

URL: http://dx.doi.org/10.5539/res.v7n6p61

\begin{abstract}
The article reviews the problem of social engagement of Kazakh youth. Having analyzed Russian and foreign literature, the authors have come to conclusion that at present there is no unified definition of this term. The experimental part of the work has studied the social engagement of Kazakh students and revealed their motives for taking part in various types of socially important activities. The conclusion based on the results of the survey has been made.
\end{abstract}

Keywords: engagement, social engagement, students

\section{Introduction}

The problems of social engagement of the youth and the analysis of its specific demonstration have been interdisciplinary issues for many years. At various times, the society treated the concept of socially engaged individual in different ways, so the attempts to analyze it overall and its components were unsuccessful. At present, the Kazakh youth has a controversial status. On the one hand, it is characterized as socially immature and politically passive (low level of civil society: the rights of the citizens are insufficiently protected, there are few political and civic associations and their passivity, immature political views). On the other hand, the youth is considered as innovative resource and the subject of social transformations.

However, the recent years demonstrated the development of youth movements and communities, and consequently, the increasing awareness of the importance of social engagement in the process of formation and development of civil society. Self-organizing and self-realization of such youth is carried out through the activities of youth organizations, the implementation of social projects and initiatives. However, in this country the percentage of socially engaged young people is very low.

This sociological research studies the level of social engagement of Kazakh youth.

\section{Literature Review}

To formulate the initial theoretical views of this work, the analysis of nature and meaning of the concept "social engagement" was implied.

Due to the transition of modern society to market economy and new conditions of life in public consciousness, many scientific concepts have changed as well. One of these concepts, "public engagement", was relevant in the Soviet period. For modern society, the concept "social engagement" is applied. Conditions of modern life fill this term with new content. In some philosophical, sociological, and educational researches public and social engagement are often considered as synonyms (Bekhterev, Arkhangelskii, Vulfov, \& Malkovskaya).

The dictionary edited by I. T. Frolova defines social engagement as the operation of the individual in the society, associated with knowledge, goal setting, changing the reality, and the transition of interest into activity. It is also closely connected with active human nature, the contradiction between life conditions and objective needs of the individual and is aimed at improving the life of the society (Frolova, 1986).

V. F. Bekhterev considers public (social) engagement as the quality of an individual, which displays in the consciousness of the need for socially significant activities and the readiness for this activity, the ability to act unselfishly for the common good (Bekhterev, 1985).

According to K. A. Abulkhanova-Slavskaya, an individual demonstrates social engagement in his relation to the activities and consists in the ability to put forward new social challenges and take responsibility for their 
implementation (Abulkhanova-Slavskaya, 1980).

V. G. Mordkovich notes that the meaning of this concept lies in the fact that social engagement is a significant social quality of a person, his "active essence." Being a human activity, social engagement acquires the status of the phenomenon of social reality (Mordkovich, 1981).

L. N. Zhilina and N. T. Frolova define social engagement as a psychological quality of a person. "It is an attraction to everything happening around, taking interest not only in the events nearby, among the employees, but also in a town, city, village, country, worldwide. The individual demonstrates such attraction in his labor, experience, social work, and relationships with friends" (Zhilina \& Frolova, 1969).

A. V. Petrovsky believes that social engagement is an active life attitude of a person, expressed in his adherence to ideological principles, consistency in defending his ideas, the unity of words and actions (Petrovsky, 1992).

S. L. Komarova, researching the relationship between the individuals in political activity, considers social engagement as the intensity of the assimilation of potential social possibilities for a decent life by an individual and the volume of participation in the progress of human society. According to S. L. Komarova, social activity involves the formation and development of motives and conditions, encouraging the individual to achieve socially important goals (Komarova, 2002). Social engagement of members of the society determines the level of expanded reproduction of material and intellectual values, and thus, increases the possibility to improve the individual and the society (Komarova, 2002).

The problem of increasing the youth social engagement in labor and sociopolitical activity was the main issue of the works by outstanding Soviet educators and statesmen P. P. Blonsky, N. K. Krupskaya, A. V. Lunacharsky, A. S. Makarenko, V. A. Sukhomlinsky, K. D. Ushinsky, S. T. Shatsky and others.

In English scientific literature the terms "civic engagement" and "public engagement" are of similar meaning. Social, civic and public activities have a number of different definitions.

The report prepared by the Carnegie Corporation confirms the lack of agreement on the term "civic engagement". According to Gibson, the absence of consensus on the meaning of this term proves the immaturity in this sphere (Gibson, 2000).

Considering the concepts of civic and public engagement, one cannot but pay attention to the fact that researchers formulate the definitions, depending on their personal points of view and interests.

Below there are definitions of civic and public activities.

According to Thomas Ehrlich (2000), "Civic engagement means working to make a difference in the social life of our communities and developing the combination of knowledge, skills, values and motivation to make that difference. It means promoting the quality of life in a community, through both political and non-political processes."

Civic and public activities are regarded as social work. Civic engagement is defined as participation in voluntary service of the community, both individually and as a team member. For example, Diller (2001) gives the following definition: "Social engagement is an individual's duty to embrace the responsibilities of citizenship with the obligation to actively participate, alone or in concert with others, in volunteer service activities that strengthen the local community."

A. Adler wrote about "social interest", considering it as a guiding force, being the core of all human endeavors. According to Adler, social interest is a kind of "social feeling", "sense of community", "solidarity", which are based on a positive inclination to social life and includes the significance of membership in human society, that is, a sense of identification with the humanity and similarity with every member of the human race. Adler believed that the backgrounds of social interest are inherent. However, it does not appear automatically and requires conscious development. Social interest is not constant and can be formed (Mosak, 1991).

According to Van Benshoten (2001), "social engagement may be defined as the means by which an individual, through collective action, influences the larger civil society".

Dean Robert Hollister (2002) connects civic engagement with active social attitude, though his definition also emphasizes the importance of collaboration with a group of other people, "Active citizenship is about collective action more than the behavior of individuals. It is about collaboration, about intense joint activity...pursuing community issues through work in all sectors, not just government."

To find a proper definition of this term, the researcher of social capital David Crowley focused his attention on the concept "social changes". In his opinion, civic engagement of the society causes social changes. "Social 
engagement describes how an active citizen participates in the life of the community in order to help shape its future. Ultimately, social engagement has to include the dimensions of social change."

The authors mentioned above in some ways limited the concept of civic and public engagement, while other researchers, on the contrary, considered it in a broader sense. Robert Putnam, along with civic and public engagements, studied the refusal to participate in civic activities. In his view, the lower level of public activities is accompanied with a decrease in club meetings, get-togethers with friends, committee session, going to church, charity and participation in elections. Thus, civic and public engagements include all activities of American society. He uses "civic engagement" to describe the whole range of activities that contribute to social capital (Putnam, 2000).

Carpini (2003) also defines this term in a broad sense. In his opinion, civic engagement implies individual and collective actions aimed at solving socially important problems. Forms of civic and public engagement can vary from individual voluntarism to participation in organizational issues of election campaigns. It assumes the effort to solve the problem and interaction with other people or institutions of representative authorities.

The analysis of a range of works on this problem shows that Bekhterev and Khristova (1972) suggested the most reasonable definition of social engagement of an individual, "Social engagement of the individual is the highest form of engagement. It is a quality of a person, which displays in the consciousness of the need for socially significant activities, in readiness for this activity. Socially engaged individual acts consciously, showing the ability to adapt to reality and change it; he behaves unselfishly for the common good and during this interaction with reality changes himself." This definition is the basis for our research.

The study and development of social engagement of a student is one of the most important tasks of educational and upbringing process in which higher school plays a special role. The most significant social function of a university as an educational institution is to create conditions for social engagement of a student, implementation of his abilities, professional development, allowing him to contribute to scientific, technological, and social progress of civil society.

We believe that the development of social engagement of a person is carried out primarily within the leading activity of a certain age period, which is associated with the appearance of major mental and social features of an individual. Common leading activity for students is the social situation that is, getting professional education in process of studying at the university.

Education and vocational activity is a specific type of activity aimed at a student as a subject for development and formation of his personality as a professional (Slastenina, 2006). On the one hand, it is a kind of cognition; on the other hand, it is a type of development of practical professional activities, based on the reflection-transforming activity of the subject.

Students demonstrate the dynamics of social engagement in the assimilation of their role of the subject of social engagement in educational and professional functions in the process of self-determination and further and self-development on the basis of harmonization of personal and social priorities, the implementation of social tests. Since the subject is the one who is able to authorize the activity, get involved into the process of its design and construction as a whole, and set his own vision of its image and the sample (Kudryavtsev, 2014). Assimilation of the position of active subject of engagement in education and vocational activities is a transition to authorship of its internal design and external implementation at collaboration with the educational environment.

Social engagement of a student is a complex state and at the same time it is an integrated ability to carry out conscious determined interaction with the society. An individual transforms himself and the reality for common and his own good by education and vocational activities, being guided by social and moral values. Internal source of social engagement for any person are his necessities for things, objects, conditions, without which life activities are impossible or are interpreted so.

When the necessities are conscious and objectified, the person gets a motive for action. Motive is a material or ideal object, which encourages and directs to itself the activities (Rubinstein, 2000). Motivation, in turn, can be defined as an inner inspiration for activity originating from desires, interests, and attitude of a person.

K. A. Abulkhanova-Slavskaya emphasizes that motivation stimulates the system of interaction between an individual and conditions of his life, that is, the way of life chosen by a person is brought about (Abulkhanova-Slavskaya, 1991). Thus, motives of the activity are connected with the orientation of a person and the values which define the ways and means for the satisfaction of needs.

The concept "stimulus", unlike "motive", is related to the external factors, inducing a person to act. Stimulation 
involves the creation of conditions in which social activity, giving certain constant results, becomes necessary and sufficient condition for satisfying important and socially determined human needs, the formation of his motives.

In 2014 Research Center "Youth" carried out the investigation "Development of volunteerism in the Republic of Kazakhstan". According to this research, the motives for participation in volunteer activities, held in different cities of Kazakhstan, have the following hierarchy: inner psychological need to be needed-26.7\%, service to the idea-22.2\%, need for communication- $17.9 \%$, interest in the visual appeal-14.2\%, possibility of interesting leisure $-12.3 \%$, chance to find new friends and hobbies $-12.3 \%$, financial rewards $-10.9 \%$, the way to share experiences- $10.1 \%$, career, authority and self-realization- $6.8 \%$, confirmation of independence and maturity-3.4\%, protection of personal interests-2.4\%, undecided-7.6\% (Research Center "Youth", 2014).

Three most popular responses in all age groups are: psychological need, service to the idea, and the need to communicate.

\section{Methods and Data}

The objective of the research: This investigation was carried out to study the level of social engagement of students and the main motives for active or passive participation in social engagement.

The following tasks were under consideration:

First, to analyze the nature and meaning of the concept "social engagement";

Second, to define the level of social engagement of students in different spheres of life: science, sport, culture, labor, and public;

Third, to formulate the motives, inducing the students for various kinds of social engagement;

Fourth, to analyze the reasons for passiveness of students.

This sociological research was carried out by questionnaire poll among the students of the Shakarim State University, Semey, East-Kazakhstan. The selection was 100 people (61 girls and 49 boys), aged 17-21.

The questionnaire includes 19 points. The first six questions study the level of social engagement of students in various activities, that is, science, sport, culture, labor, and public. Ten points reveal the motives for active or passive participation in social engagement. The last three questions touch upon personal information of students. The analysis of understanding the concept and level of social engagement was done among the students of 1-4 courses.

\section{Results and Discussion}

The results of the poll are shown below.

Let's consider separately the level of engagement of students in various socially important activities of university period.

Scientific and research activities. Less than a third of the respondents take part in scientific conferences and other scientific events of the university. The most active of them are third and fourth-year students (28\%).
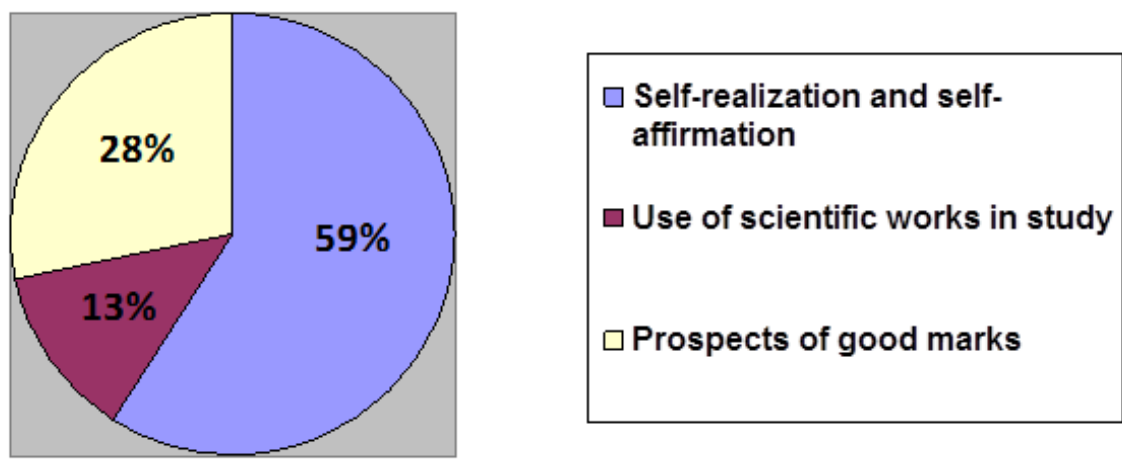

Figure 1. The main motives for scientific activities 
The main motive encouraging the youth to be engaged in science is the desire for self-realization and self-affirmation (56\%), the possibility to use scientific works in study (57\%), and the prospect of good marks $(27 \%)$.

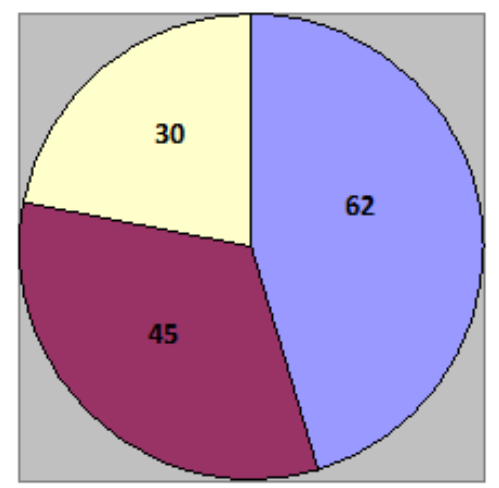

Absence of time

Lack of time

\section{Absence of necessary abiliities}

Figure 2. Motives for passiveness in scientific events

The main reasons for refusal to participate in scientific events are the absence of interest (62\%), lack of time $(45 \%)$, and the absence of necessary abilities (30\%). The analysis of the results shows that motivation for scientific activities is low, as the engagement in this sphere is connected with external factors, and passiveness, on the contrary, is caused by inner ones.

Labor activities. Labor activities include such events as community work days, planting trees, etc. Most answers were positive (66\%). $47 \%$ of the first-year students and $35 \%$ of second-year students are engaged in this activity, and the number of third and fourth-year students are significantly less ( $33 \%$ and $24 \%$, respectively).

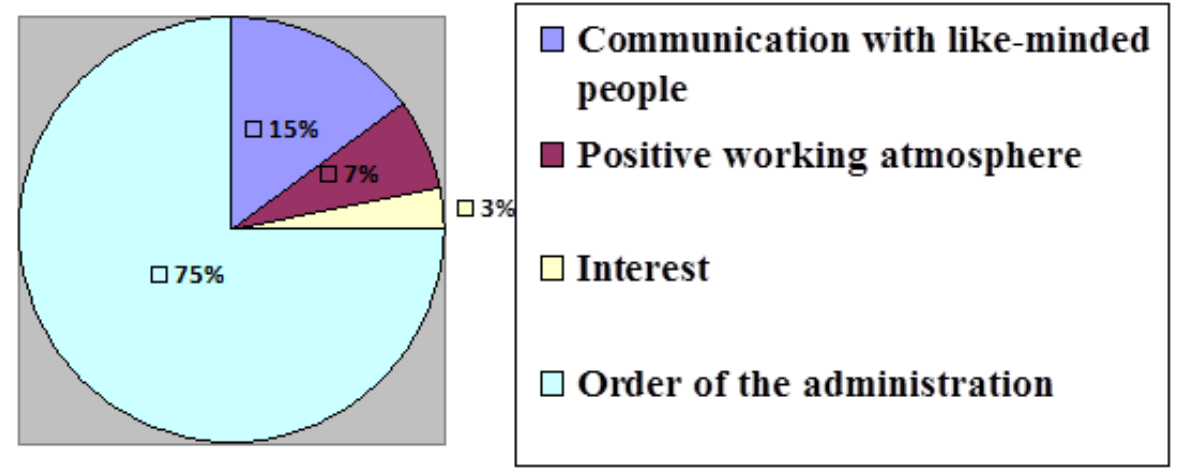

Figure 3. Motives for labor activities

Participation in such events is organized mainly by the authorities of the educational institution, $85 \%$ of students state this. Other motives are interest (16\%), communication with like-minded people $(12 \%)$, and positive working atmosphere $(10 \%)$.

As for passiveness of students in labor activities, the most common reasons are the lack of interest (56\%), lack of time (38\%) and information about the events (21\%).

Figures 3 and 4 show the rates of various motives for active and passive participation in labor activities. 


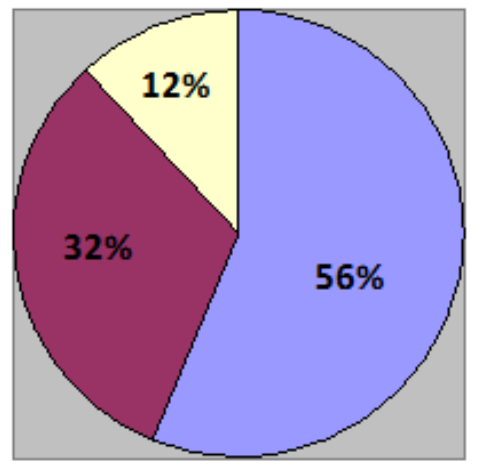

\section{Absence of interest}

\section{Lack of time}

\section{Lack of information about the} events

Figure 4. Reasons for passiveness in labor activities

Mass and cultural activities. $36 \%$ of respondents are active in this sphere. First and third-year students are the most active of all ( $46 \%$ and $42 \%$, respectively).
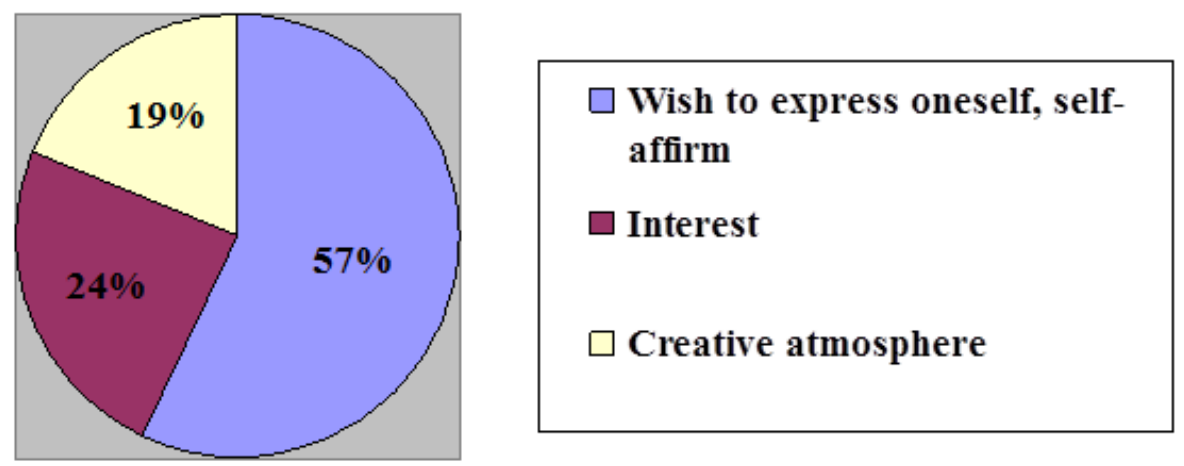

Figure 5. The main motives for participation in mass cultural activities

Figure 5 shows that the main motive for taking part in such events is the wish to express oneself, self-affirmation $(85 \%)$, interest $(56 \%)$, and creative atmosphere $(26 \%)$. The results demonstrate that the motive for self-realization dominates in the choice of mass and cultural activities.

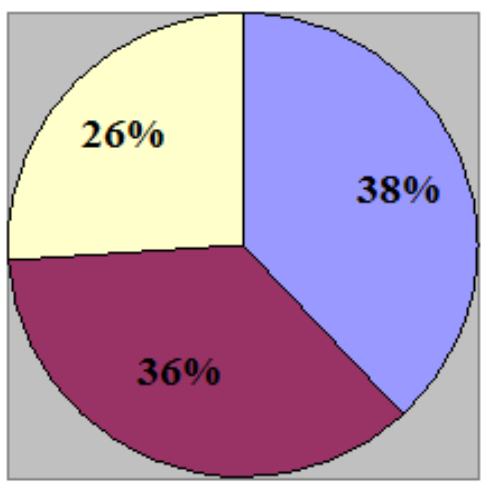

Fear of failure and uneasiness

\section{Lack of time}

\section{Absence of abilities}

Figure 6. Motives of passiveness 
Students explain their passiveness in this sphere by the lack of time (36\%), fear for failure and uneasiness (32\%), absence of abilities or possibilities (27\%).

Public activities. 18\% of respondents take part in socially important events (visiting children's home, nursering home, etc.). Third and fourth-year students are the most active of all (30\% and 32\%, respectively).
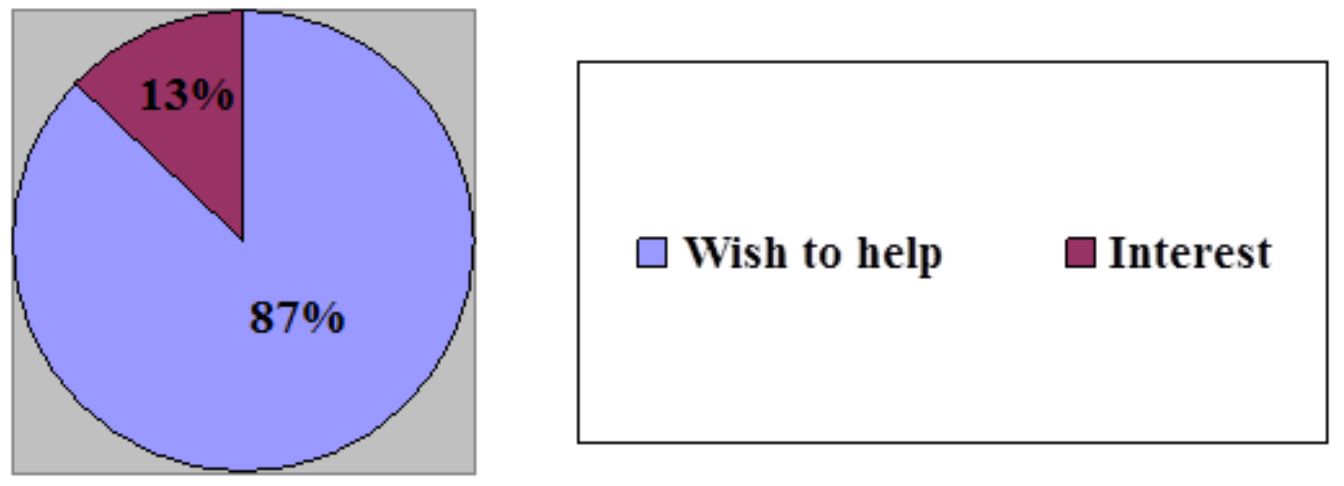

Figure 7. Motives of engagement in public activities

The main motive of engagement in this sphere is the wish to help. Interest takes the second place (29\%).

It should be mentioned that students are the least passive in these activities. But their sincere wish to help is a positive sign.
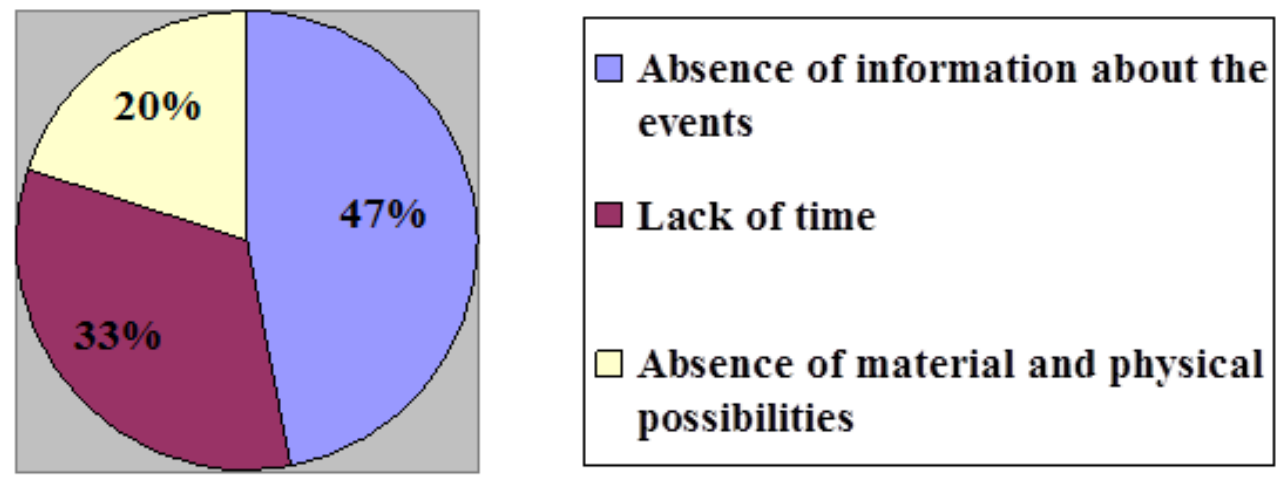

Figure 8. Reasons for refusal to participate in public activities

The answers about the motives for refusal to participate in this activity (Figure 8) are rated as follows: absence of information about the events (47\%), lack of time (40\%), absence of material and physical possibility (25\%).

Sport activities. Only $29 \%$ of the respondents take part in sport events held by the university. Most of them are first and third-year students (43\% and 39\%). The main motive for $95 \%$ of respondents is interest. The second place takes the desire for self-affirmation and self-realization (53\%). The other motives are the atmosphere of contest $(13 \%)$ and recognition oneself as a team member (15\%). Most young people explain the refusal to participate in sport events by the lack of time (51\%), absence of abilities or possibilities (42\%). Other reasons of passiveness are fear for failure and lack of self-confidence (22\%) and absence of interest (19\%). Such answers prove that inner motives induce the students to take part in sport events, and the reasons of passiveness are objective. 


\section{Conclusions}

1) The survey has shown that social engagement of university students is at a low level, since the percentage of participation in each type of events hardly exceeds $30 \%$. Labor activity is an exception, since it is not voluntary. It was also found out that fourth-year students are more passive than the others. It can be explained by preparation for state examinations and defense of a graduation project, as well as the shift of their interest to their future professional functions.

On the whole, Kazakh students are not associative and see no sense in social engagement. They take little interested in what goes beyond private life. Students are weakly involved in environmental movements and unlike foreign people of the same age are not concerned about security issues and social injustice; position of the youth in the fight against social illnesses of modern Kazakh society is indistinct.

2) The survey has found out that boys are more active in sports, mass cultural spheres ( $40 \%$ and $60 \%$, respectively), and girls take part in science, labor and public events ( $26 \%, 70 \%$ and $48 \%$, respectively).

3) Students, active in a certain events, take part in others as well; vice versa, passive youth remains indifferent to other activities. Thus, the engagement is really low.

4) In mass cultural, social and sport activities, the students demonstrate quite formed and conscious motives for participation, as the motivating factors are inner motives. Participation in science and labor is stimulated by external factors; most students explain the refusal to take part by the absence of interest. Consequently, the engagement in these areas is generated mainly by external motivators, and passivity, on the contrary, by internal ones.

In conclusion it should be mentioned that the results are not common for all students and they are typical only for those who participated in the survey.

There is a number works on this problem in Russian and foreign literature. However, many issues still need consideration. Further studies should include the following directions: to clarify the definition of the concept and the structure of social engagement as a personality quality, to research the ways of formation of inner motives and the system of external stimulation of the youth social engagement, to encourage both young and old people for social engagement, to study the features of this phenomena in social networks.

\section{References}

Abulkhanova-Slavskaya, K. A. (1980). Activities and personality psychology. M.

Abulkhanova-Slavskaya, K. A. (1991). Strategy of life. M.

Analytical report on the results of sociological research "Development of volunteer movement in the Republic of Kazakhstan". (2014). Astana: Research center "Youth".

Bekhterev, V. F. (1985). Development of public engagement of school children. Krasnoyarsk.

Crowley, D. Summary of youth engagement strategy. Woburn, MA: Social Capital, Inc.

Della, C. M. (2003). Definitions of social engagement. Retrieved February 12, 2003, from www.campuscares.org/serve/definitions $3 . h t m l$

Diller, E. C. (2001). Citizens in service: The challenge of delivering social engagement training to national service programs. Washington, DC: Corporation for National and Community Service.

Ehrlich, T. (2000). Civic responsibility and higher education. Oryx Press.

Frolova, I. T. (1986). Dictionary of philosophy (5th ed.). M.

Gibson, C. (2000). From inspiration to participation: A review of perspectives on youth social engagement. New York: Carnegie Corporation of New York.

Hollister, R. (2002). Lives of active citizenship. Inaugural talk, John DiBiaggio chair in citizenship and public service. Tufts University.

Khristova, I. C. (1972). Methods of developing social engagement of individual in socialism. M.

Komarova, S. L. (2002). Optimization of relationship between subjects of political activities ( $\mathrm{PhD}$ thesis). M.

Kudryavtsev, V. T. (2014). Formation of activity subject and possibilities of educational system. Retrieved September 10, 2014, from http://www.tovievich.ru/book/4/240/1.htm

Mordkovich, V. G. (1981). Labor activity: "theory" of a single empiric change. In Social engagement. Chelyabinsk. 
Mosak, H. H. (1991). "I don't have social interest”: Social interest as construct. Indiv. Psychol., 47(3), 309-320.

Petrovsky, V. A. (1992). Psychology of nonadaptive activity. M.: Gorbunok.

Putnam, R. (2000). Bowling alone: The collapse and revival of American community. New York: Simon \& Schuster. http://dx.doi.org/10.1145/358916.361990

Rubinshtein, S. L. (2000). Basics of general psychology. StPb.

Slastenin, V. A. (2006). Pedagogics of vocational training. M.

Van B. E. (2001). Social engagement for people of all ages through national service (Unpublished manuscript).

Zhilina, L. N., \& Frolova, N. T. (1969). Thought.

\section{Copyrights}

Copyright for this article is retained by the author(s), with first publication rights granted to the journal.

This is an open-access article distributed under the terms and conditions of the Creative Commons Attribution license (http://creativecommons.org/licenses/by/3.0/). 